\title{
PERCEPÇÃO DOS GESTORES DAS MICRO E PEQUENAS EMPRESAS MINEIRAS DO SETOR FARMACÊUTICO SOBRE OS ARTEFATOS GERENCIAIS \\ TRADICIONAIS E INOVADORES E AS PERSPECTIVAS DA SUA ADOÇÃo
}

\author{
PERCEPTION OF THE MANAGERS OF THE MICRO AND SMALL MINING \\ COMPANIES OF THE PHARMACEUTICAL SECTOR ON THE TRADITIONAL \\ AND INNOVATIVE MANAGEMENT ARTS AND THE PERSPECTIVES OF THEIR \\ ADOPTION
}

Recebido: 16/08/2016 - Aprovado: 14/04/2017 - Publicado: $27 / 062017$ Processo de Avaliação: Double Blind Review

\author{
Fernanda Medeiros Spacek ${ }^{1}$ \\ Graduada em Ciências Contábeis \\ Universidade Federal de Uberlândia (UFU) \\ fernanda.spacek@gmail.com \\ Graciela Dias Coelho Jones \\ Doutoranda em Administração de Empresas \\ Universidade Presbiteriana Mackenzie, MACKENZIE, Brasil \\ Mestrado Profissional em Gestão e Estratégia em Negócios \\ Universidade Federal Rural do Rio de Janeiro \\ graciela.jones@ufu.br \\ Vanessa Ramos da Silva \\ Mestre em Ciências Contábeis \\ Universidade Federal de Uberlândia \\ vanessaramossilva@hotmail.com
}

RESUMO: O objetivo do artigo é identificar a percepção dos gestores das Micro e Pequenas Empresas (MPEs) mineiras do setor farmacêutico sobre os artefatos gerenciais tradicionais e inovadores e as perspectivas da sua adoção. Para tanto, foi realizada uma pesquisa do tipo survey com 29 farmácias de uma cidade de grande porte localizada no estado de Minas Gerais, Brasil, que possuem em seu Cadastro Nacional de Pessoa Jurídica (CNPJ) a confirmação de que estão enquadradas no regime especial de Micro e Pequenas Empresas, conforme Lei $\mathrm{n}^{\mathrm{o}} 9.317$ de 05 de dezembro de 1996. Por meio deste estudo de abordagem quantitativa, verificou-se que as empresas estudadas apontaram que os gestores têm noção geral sobre o assunto, porém, falta conhecer melhor as contribuições proporcionadas pela adoção dos artefatos, assim como as suas aplicações. Concluiu-se que existe uma escassez de estudos e artigos acadêmicos relacionados ao setor farmacêutico nas bases de dados pesquisadas. Espera-se que o presente estudo sirva de contribuição teórica como fonte de informação para pesquisas futuras. Como contribuição prática, espera-se que o estudo

\footnotetext{
${ }^{1}$ Autor para correspondência: Universidade Federal de Uberlândia. Progresso, Uberlândia - MG, CEP: 38408-100.
} 
desperte gestores do setor sobre a importância dos artefatos, bem como, de sua adoção para auxiliar no processo de tomada de decisão.

Palavras-chave: Artefatos gerenciais; Artefatos inovadores; Artefatos tradicionais; Setor farmacêutico.

ABSTRACT: The objective of this article is to identify the perception of managers of Micro and Small Enterprises of the pharmaceutical sector, located in Minas Gerais, about traditional and innovative management artifacts and the prospects of its adoption. To do so, a survey research was conducted with 29 pharmacies in a large city in the state of Minas Gerais, Brasil, which have in their National Registry of Legal Entities the confirmation that are framed in the special arrangements for Micro and Small Business, according to Law number 9.317 of December 05, 1996. Through this quantitative approach study, it was found that the companies surveyed indicated that managers have understanding on the subject, however, lack better understanding of the contributions provided by the adoption of the artifacts, as well as their applications. It was concluded that there is a lack of studies and academic papers related to the pharmaceutical sector in the surveyed databases. It is hoped that this study has theoretical contribution as a source of information for future research. As a practical contribution, it is expected that the study awaken sector managers on the importance of the artifacts as well as their adoption to assist in the decision-making process.

Keywords: Management artifacts; Innovative artifacts; Traditional artifacts; Pharmaceutical industry.

\section{INTRODUÇÃO}

O desenvolvimento do mercado financeiro e das empresas no ambiente nacional e internacional exige das organizações iniciativas que permitam um aprimoramento em seus modelos gerenciais. Conforme Cunha et al. (2010), o dinamismo do mercado faz com que as organizações adotem ferramentas gerenciais eficientes, visando garantir competitividade e sobrevivência. Carvalho Júnior et al. (2009) enfatizam que, com o crescimento da competitividade, dos preços, a contabilidade se torna uma ferramenta cada vez mais utilizada no âmbito gerencial, e busca adequar à gestão de custos, tornando-se indispensável para a sobrevivência das empresas.

Hashimoto e Fonseca (2009) afirmam que o comércio farmacêutico apresenta finalidades específicas, pois representa o principal meio de distribuição de medicamentos. $\mathrm{O}$ setor está inserido em um cenário que apresenta limitações, o grande motivo das pequenas empresas do setor farmacêutico não acompanhar o crescimento do setor, e consequentemente, assistirem as grandes redes se multiplicando, é a falta de planejamento, assim como a inexperiência dos proprietários e gestores da empresa.

A presente pesquisa tem como objeto as farmácias classificadas como Micro e Pequenas Empresas (MPEs), de acordo com a Lei $\mathrm{n}^{\circ}$ 9.317/1996, que regulamenta o 
tratamento diferenciado, simplificado e favorecido, aplicáveis às microempresas e às empresas de pequeno porte, relativo aos impostos e às contribuições que menciona.

Oliveira e Papa (2009) afirmam que o planejamento orçamentário e gerencial, possibilita à organização verificar quantos e quais pontos deverão ser trabalhados para alcançar seus objetivos e metas. Estudos realizados com modelos de planejamento e orçamento (VILAS BOAS, 1998; JONES, 2005, SILVA, 2005; LAVARDA, 2009) identificam que eles auxiliam na gestão interna das organizações, contribuindo na compreensão e conhecimento de itens a serem trabalhados para obter melhores resultados. Ribeiro (2012) considera que os artefatos gerenciais se subdividem em dois: os tradicionais, que não trabalham questões dinâmicas; e os inovadores, que abrangem informações importantes e detalhadas, auxiliando em alto nível na decisão.

Neste contexto, a questão que norteou a presente pesquisa resume-se em: qual é a percepção dos gestores das MPEs mineiras do setor farmacêutico sobre os artefatos gerenciais tradicionais e inovadores e as perspectivas da sua adoção?

Desse modo estudo tem por objetivo levantar o nível de percepção dos gestores das MPEs mineiras do setor farmacêutico sobre os artefatos gerenciais tradicionais e inovadores e as perspectivas da sua adoção.

Para tanto, foi realizada uma pesquisa com 29 farmácias, de uma cidade de grande porte, localizadas em Minas Gerais, que possuem em seu Cadastro Nacional de Pessoa Jurídica (CNPJ) a confirmação de que estão enquadradas no regime especial de MPEs, conforme Lei $n^{\circ}$ 9.317/96.

A importância em se estudar o assunto respalda-se na dificuldade apresentada por MPEs em se relacionar com assuntos sobre gestão, quando comparadas a facilidade da maioria de grandes organizações em lidar com alguns artefatos gerenciais.

\footnotetext{
Grandes empresas possuem uma maior capacidade inovadora e de resistência em relação às pequenas, já que entre as grandes o ritmo de introdução de inovações seria mais intenso. Entretanto, faz-se necessário considerar com mais ênfase a capacidade inovadora das Pequenas e Médias Empresas (PMEs) (BRASIL; NOGUEIRA; FORTE, 2011, p.1).
}

Espera-se que os resultados obtidos no presente estudo contribuam para despertar interesse e curiosidade das empresas do setor farmacêutico em trabalhar com artefatos gerenciais. 


\section{ARTEFATOS GERECIAIS}

Nascimento et al. (2010) afirmam que as informações importantes para a tomada de decisão contêm diversas variáveis que causam impactos significativos.

Para Ribeiro (2012), os sistemas de custeios tradicionais oferecem informações detalhadas, porém podem não auxiliar na avaliação do aumento ou diminuição do valor econômico da empresa. Diehl e Souza (2008), este custeio utiliza o volume de vendas para obter os custos da organização. Os sistemas de custeio tradicionais chamado custeio por absorção, chegaram à década de 1980 carregados de críticas, principalmente dos gerentes, usuários da informação.

Para Ribeiro (2012) os inovadores são dinâmicos e permitem calcular o custo de diversos objetos, nomeadamente, produtos, operações e canais de distribuição levando em conta a sua diversidade e também complexidade. Nascimento et al. (2010), considera que os artefatos gerenciais evidenciam elementos e aspectos únicos, e almejam, em cada artigo e opinião dos autores, medirem o desempenho organizacional.

\subsection{ARTEFATOS GERENCIAIS INOVADORES}

\section{Balanced ScoreCard (BSC):}

O modelo de artefato BSC é diferenciado das demais ferramentas tradicionais, conforme Frezatti (2008), pois não pode fornecer informações capazes de gerar um valor econômico futuro à organização. Costa (2006) considera que, ao contrário das ferramentas gerenciais tradicionais, o BSC trabalha a união do planejamento estratégico com o operacional, pois explicita cada item de desdobramento do ganho competitivo em cada ação praticada. Essas ações mandam recursos operacionais e financeiros que deverão estar contemplados no planejamento operacional e, consequentemente, no orçamento. Anderson e Frezatti (2007) utilizam em seu trabalho classificações dos artefatos gerenciais e, por sua vez, consideram o BSC como um modelo contemporâneo.

Frezatti (2008) relata que, com um mercado cada vez mais complexo, as empresas necessitam de ferramentas que possam fornecer informações em longo prazo, unindo-as ao plano estratégico tático da mesma. Wernke e Bornia (2001) afirmam que, com a abertura do mercado internacional e a globalização, as organizações vêm a necessidade de se atentar para aspectos não somente financeiros para medir o desempenho da organização. Sendo assim, a contabilidade passa a ter um papel mais gerencial e menos restrito a dados financeiros. Surge então a obrigatoriedade de se obter uma determinada flexibilidade à estratégia da empresa, 
fornecendo informações que auxiliem os gestores na tomada de decisão dentro da organização. O BSC é uma ferramenta de fim gerencial que, manejada de determinada forma, pode manter a estratégica alinhada ao modelo gerencial da organização, conforme Frezatti (2008).

O BSC é um modelo criado para fornecer dados intangíveis da organização, tais como: produtividade, qualidade, custos de inventário, entre outras, buscando uma melhor medição de desempenho. Entretanto, para Costa (2006), o BSC não é um modelo padrão a ser aplicado de uma maneira única a várias empresas. O BSC trabalha com particularidades de cada organização, sua visão e missão, assim, o modelo de BSC deve ser construído de acordo com características da cultura, estratégia e valores da organização. “O tradicional sistema contábil de custos, baseado em premissas de produção de longo prazo de produtos padrões, sem mudanças de características e especificações, não era mais relevante no novo ambiente competitivo" (COSTA, 2006, p. 90).

\section{Custeio Baseado em Atividades (ABC):}

Com o avanço tecnológico, as inovações nos sistemas de informações e demais mudanças organizacionais motivam os pesquisadores e profissionais a enfatizar o modelo de custeio $\mathrm{ABC}$, pois há uma chance de que possa melhorar, programar ou inovar as análises feitas pelos modelos tradicionais, de acordo com Nakagawa (2001). Alguns outros autores como, Anderson e Frezatti (2007) destacam a classificação do modelo ABC como sendo contemporâneo. Para Silva, Alves e Cogan (2007), esse artefato gerencial difere-se dos métodos tradicionais, pois um de seus aspectos é acumular os custos existentes na organização de uma maneira diferenciada.

\footnotetext{
Enquanto o sistema tradicional utiliza um modelo de acumulação de dois estágios, mediante a acumulação dos custos por função ou departamento (primeiro estágio) e rateio desses custos pelos produtos mediante um fator volumétrico de medição (segundo estágio), o custeio $\mathrm{ABC}$ parte do princípio de que os recursos indiretos e de apoio (administrativo e de vendas) fornecem capacitação para o desempenho de atividades, em vez de gerarem custos para serem alocados (SILVA; ALVES; COGAN, 2007, p. 6).
}

$\mathrm{O}$ modelo $\mathrm{ABC}$ considera que a empresa possui recursos e gastos que são utilizados em suas devidas atividades, e não apenas pelos itens fabricados, considerados métodos tradicionais. Diehl e Souza (2008) denotam que o tratamento diferenciado dado aos custos se resume pelo fato de que no $\mathrm{ABC}$ as atividades são as geradoras de custos, e fazem isso 
quando consomem os recursos existentes. Nos modelos tradicionais, consideram que os produtos/clientes consomem os recursos e geram os custos da organização,

A seguir, é apresentada a Figura 1 que ilustra a situação acima citada:

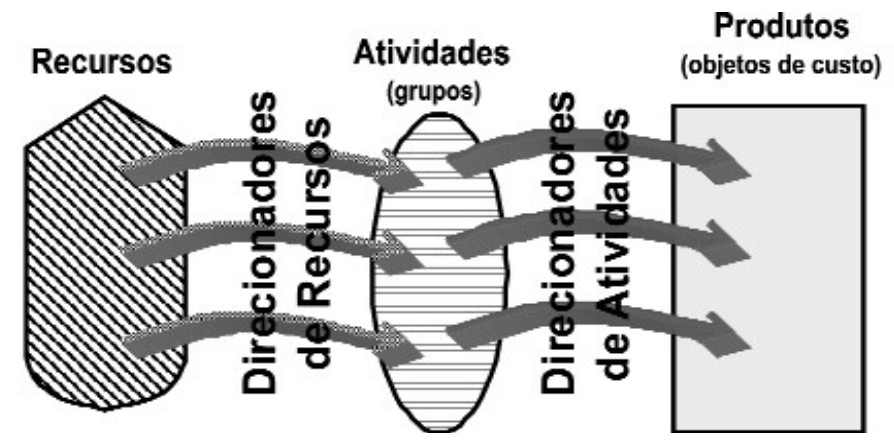

Fonte: Diehl; Souza; 2008,p. 5

Figura 1: Funcionamento ABC

Ribeiro (2012) afirma que este artefato gerencial utiliza os custos indiretos de maneira delicada e específica, possibilitando calcular o custo real, por não considerá-los como custos de período. Na teoria, esse método de custeio é simplificado, se resumindo em uma nova metodologia que busca oferecer uma agilidade na análise estratégica dos custos inseridos nas atividades e processos de produção da organização, conforme Nakagawa (2001). Outro aspecto diferente é que esse custeio evidencia cada causa do custo específico, identifica de qual atividade ele pertence para poder alocá-lo ao objetivo, e não fazê-lo por rateio, como no caso dos tradicionais. É indicado para organizações que possuem grande mix de produtos, com alta parcela de custos indiretos, conforme Diehl e Souza (2008).

\section{Valor Econômico Agregado (EVA):}

Angonese, Santos e Lavarda, (2011) destacam as críticas relacionadas aos custeios tradicionais, que não consideram de um item específico, o "valor", dentro da organização, surgindo, assim, a necessidade de criar algo que contemple esse fator. Stern Stewart (1999) registra o artefato EVA (Economic Value Added). Backs (2002) afirma que o EVA utilizou os princípios e teoria financeira, e tornou-a moderna, auxiliando os gestores que não possuem o conhecimento especifico em finanças e suas aplicações. Guerreiro, Cornachione Junior e Soutes (2010) denominam o sistema EVA como um artefato moderno, utilizado pelas organizações. Não obstante, esse artefato gerencial também se classifica como contemporâneo na pesquisa de Anderson e Frezatti (2007).

Para Ribeiro (2012), os métodos de custeio tradicionais fornecem informações específicas, mas isso não contribui para analisar o aumento ou queda do valor econômico da empresa. O EVA tem essa finalidade de fornecer informações que criem valor econômico à 
organização. Backs (2002) afirma que o EVA surge como um artefato para calcular o desempenho, buscando a criação de valores e riquezas para os acionistas da organização.

Basso, Oliveira e Kayo (2008) evidenciam que as demonstrações financeiras possuíam imperfeições, e para corrigi-las, fizeram uso do EVA e adaptaram os dados contáveis conforme os Princípios Contábeis, almejando criar uma possibilidade de fornecer valores confiáveis, criando um cenário com uma atitude gerencial, aproximada ao máximo do esperado.

Teoria das Restrições (TOC):

Caríssimo, Matias e Callado (2012) destacam que, ao contrário das teorias tradicionais, esse artefato gerencial busca informar aos gestores que a organização deverá sempre ansiar pelo ganho e pela geração de lucro em geral. Assim como Guerreiro, Cornachione Junior e Soutes (2010), que também o classificam como moderno/inovador.

A teoria das restrições (TOC) busca identificar as áreas e atividades que restringem o processo funcional da organização, almejando melhoria constante da gestão. Para Martins e Rocha (2010), essa teoria possui três objetivos, sendo eles: a busca melhor pelos processos internos de uma organização, a otimização da utilização dos recursos escassos e, por último, aumentar o nível de lucro da mesma. Silva, Alves, Cogan, (2007) afirmam que a ideia inicial, ao desenvolver essa filosofia, foi a mesma de Eliyahu Goldratt em 1980, que buscou identificar os processos ou recursos que dificultavam alcançar a capacidade produtiva, diminuindo o resultado econômico da empresa.

Admitindo-se como premissa básica que a meta da empresa é ganhar mais dinheiro, e sempre haverá uma ou mais restrições no processo de alcance dessa meta, é possível concluir que os gestores das organizações deveriam estar concentrados no gerenciamento das restrições e não somente na redução dos custos (SILVA; ALVES; COGAN, 2007, p. 9).

Martins e Rocha (2010) ressaltam que para efetuar o primeiro objetivo desta teoria, é necessário identificar os pontos de restrições do processo de produção, e então se deve gerenciá-los para encontrar um equilíbrio na capacidade produtiva da empresa. Evidenciado isso, passa-se a conhecer a restrição do processo, que diminuía o resultado da organização. Silva, Alves e Cogan (2007) destacam que qualquer organização possui uma ou mais restrições, caso contrário, os lucros da empresa seriam infinitos.

Com as definições já apresentadas, faz-se necessário representar o modelo decisório, composto por 5 passos (Quadro 1), explicitados a seguir:

REMIPE- Revista de Micro e Pequenas Empresas e Empreendedorismo da Fatec Osasco V. 3, N¹, jan.-jun. 2017. 


\begin{tabular}{|l|l|}
\hline $\begin{array}{l}\mathbf{1}^{\mathbf{0}} \text { passo- Identificar as restrições do } \\
\text { sistema }\end{array}$ & $\begin{array}{l}\text { Deve-se verificar quais são as restrições presentes nos processos, } \\
\text { identificando assim o "gargalo", ou seja, o ponto fraco, e aproveitá-lo } \\
\text { da melhor maneira possível. }\end{array}$ \\
\hline $\begin{array}{l}\mathbf{2}^{\mathbf{0}} \text { passo- Resolver como explorar as } \\
\text { restrições }\end{array}$ & $\begin{array}{l}\text { Agora o importante é decidir como trabalhar o gargalo encontrado, } \\
\text { almejando a maximização de resultados da organização trabalhada. }\end{array}$ \\
\hline $\begin{array}{l}\mathbf{3}^{\mathbf{0}} \text { passo- Subordinar demais eventos à } \\
\text { decisão anterior }\end{array}$ & $\begin{array}{l}\text { Com o gargalo identificado, o método de exploração do mesmo } \\
\text { decidido, deve-se neste passo, subordinar todos os demais processos } \\
\text { e/ou recursos ao andamento do objeto de restrição. }\end{array}$ \\
\hline $\begin{array}{l}\mathbf{4}^{\mathbf{0}} \text { passo- Elevar as restrições do } \\
\text { processo }\end{array}$ & $\begin{array}{l}\text { Se ao praticar os } 3 \text { passos citados acima, ainda permanecer alguma } \\
\text { restrição ou gargalo, deve-se eliminar ou minimizá-las, acabando } \\
\text { com os empecilhos do sistema e alcançando a maximização do } \\
\text { resultado da organização. }\end{array}$ \\
\hline $\begin{array}{l}\text { Como citado anteriormente, sempre surgirá restrições no sistema, } \\
\text { então após os passos anteriores, deve-se voltar ao } 1^{\circ} \text { passo, executar } \\
\text { todos os passos novamente, gerando um ciclo para quebrar as } \\
\text { restrições que irão surgindo no sistema. }\end{array}$ \\
\hline
\end{tabular}

Fonte: Adaptado de Silva, Alves e Cogan (2007)

Quadro 1 - Etapas para maximizar o resultado da organização

Gestão Econômica (GECON):

Para Catelli (2007), o modelo GECON surgiu com a necessidade de melhoria dos modelos de gestão, assim como os sistemas de contabilidade de custos já existentes, que não alcançavam a eficácia desejada, adequando-os à realidade das organizações e melhorando o processo de tomada de decisão das empresas. Guerreiro, Cornachione Junior e Soutes (2010) também classificam o artefato gerencial GECON como sendo um modelo inovador.

O GECON busca trabalhar o processo de planejamento, execução e controle das operações da empresa, tomado por base a missão, crenças e valores. Lima et al. (2010) denotam que o funcionamento deste artefato gerencial se resume em unir as operações da empresa, fazendo uma divisão em áreas de responsabilidades, centro e resultado de custos, identificando os níveis de eficiência e eficácia dos processos, mostrando, assim, a verdadeira contribuição individual de cada processo, uma vez que GECON considera que o Lucro é o maior e melhor medidor de desempenho empresarial.

Este modelo auxilia os gestores na tomada de decisão, melhorando os resultados com relação aos custos, tornando possíveis escolhas que considere questões como: volumes, valorização dos produtos e serviços, prazos de estoque, usando de maneira eficiente os recursos, os prazos de entrega, recebimento e financiamentos (SANTOS, 2005).

\subsection{ARTEFATOS TRADICIONAIS}

Custeio por Absorção:

Os autores Abbas, Gonçalves e Leoncine, (2012), classificaram o custeio por absorção como um método tradicional. 
Os métodos tradicionais, principalmente o custeio por absorção, recebem muitas críticas na literatura. A ênfase dessas críticas reside no fato de que o atual ambiente competitivo se alterou, sendo os métodos tradicionais criados para organizações em que amador parte dos custos era composta pelos materiais diretos e pela mão de obra direta (ABBAS; GONÇALVES; LEONCINE, 2012, p. 14).

Este método se caracteriza por alocar todos os custos de produção da organização ao custo do bem ou serviço ofertado pela mesma, estando ligados direta ou indiretamente. Diferentemente, as despesas não são incorporadas e, sim, lançadas no resultado. O método de custeio por absorção é definido pelo fato de que não há divisão entre custos diretos e indiretos. Sendo assim, há uma absorção de todos os custos que acabam sendo alocados de maneira geral ao produto.

Margem de Contribuição:

A margem de contribuição (MC) relaciona-se diretamente ao custeio variável, porém se destaca pelo fato de que faz separação do custo fixo com o custo variável. Ribeiro (2012) mostra que a margem de contribuição é a diferença entre a receita das vendas dos produtos e os custos variáveis das unidades vendidas.

Carvalho Júnior et al. (2009) afirmam que "a Margem de Contribuição é quanto sobra para a empresa pagar despesas fixas e ter lucro, pode ser chamado de Ganho Bruto sobre as vendas. Mostra para o empresário a receita que sobra das vendas para que a empresa possa pagar suas despesas fixas e gerar lucro."

Em seguida, a fórmula de cálculo da margem de contribuição:

$$
\mathrm{MC}=\mathrm{RV}-(\mathrm{CD}+\mathrm{DD})
$$

Onde:

MC: margem de contribuição

$\mathrm{RV}$ : receita de vendas

CD: custos diretos

DD: despesas diretas

Carvalho Júnior et al. (2009), consideram que como visto na equação citada, a receita de venda não poderá ser inferior à soma dos valores de despesas e custos variáveis. Interessante seria em casos excepcionais, em que a organização coloca em prática uma estratégia promocional de vendas.

Em suma, Martins e Rocha (2010) afirmam que a função desta equação é apresentar em valores quanto o produto específico contribuiu para cobrir os custos e despesas fixas da 
organização, após arcar com seus próprios custos e despesas variáveis, ou seja, é a representação de um valor do resultado individual de cada produto.

Orçamento:

Este artefato gerencial é classificado como um modelo tradicional, segundo Frezatti (2005), que destaca o fato deste modelo fixar metas anualmente, que estão relacionadas diretamente aos planos. Para Schubert (1987), o orçamento dito tradicional é caracterizado por ser dividido em dois lados - ingressos e desembolsos- e também por não se preocupar com os instrumentos e, sim, com o pessoal e despesas diversas.

Heinzmann e Lavarda (2011) denotam que o processo de orçamento é um segmento da etapa de planejamento de uma empresa e neste processo as significâncias da cultura organizacional precisam ser analisadas. Logo, nota-se que existe uma relação positiva e visível entre os aspectos de planejamento e orçamento.

Inclusive, Boas e Jones (2005) citam que o planejamento orçamentário permite à organização identificar, de maneira geral, os pontos que devem ser trabalhados, possibilitando a antecipação de resultados almejados anteriormente para determinado período de tempo. Assim verifica-se que a organização possui constantemente a necessidade de planejar e controlar suas metas e resultados para ter capacidade de conquistar um espaço no mercado. Silva e Lavarda (2009) demonstram que as empresas precisam de um planejamento, graças ao nível de complexidade das organizações, e o planejamento orçamentário auxilia os gestores na administração, fornecendo-lhes uma visão focada no futuro.

O presente artefato gerencial enquadra-se em planos estratégicos que almejam fornecer aos gestores informações que possam indicar a eficácia ou não do plano elaborado, é um modelos de curto prazo, para que possa tornar-se possível implantar eventuais mudanças, assim como a própria estratégia definida. Frezatti (2009 apud CASTANHEIRA, et al., 2012)

Schubert (1987) destaca que os dados e valores previstos no orçamento elaborado não coincidem com os números que serão apresentados conforme a organização se desenvolva durante o período orçado. São provisões e, por isso, tendem a se aproximar dos valores reais.

O orçamento também se caracteriza por fornecer dados específicos. Castanheira et al. (2012) afirmam que a verificação da observância dos princípios precisa ocorrer antes da fase inicial do planejamento, para permitir eventuais correções na estrutura organizacional e a redução de falhas no processo. 


\section{ASPECTOS METODOLÓGICOS}

A pesquisa adota o método quantitativo, que "caracteriza-se pelo emprego de instrumentos estatísticos, tanto na coleta quanto no tratamento dos dados" (RAUPP; BEUREN, 2009, p. 92).

Quanto aos objetivos, a presente pesquisa se caracteriza por ser descritiva, pois "os fenômenos do mundo físico e humano são estudados, mas não manipulados pelo pesquisador significa identificar, relatar, comparar entre outros aspectos" (RAUPP; BEUREN, 2009, p. 92).

Para se obter os dados necessários para conduzir a pesquisa, realizou-se um levantamento (survey), visto que "levanta informações que podem ser úteis para estudos futuros mais específicos ou mesmo mapear a realidade de determinada população ou amostra de empresas em relação a questões contábeis" (RAUPP; BEUREN, 2009, p. 92), os dados foram coletados por meio de questionários aplicados aos gestores das farmácias familiares.

Para realização da pesquisa foram selecionados os artefatos gerenciais: $\mathrm{BSC}, \mathrm{ABC}$, Custeio por Absorção, MC, EVA, TOC, GECON e Orçamento.

Entre os mercados existentes, decidiu-se pelo setor farmacêutico em função da escassez de pesquisas gerenciais neste setor. Para seleção das empresas analisadas, foi solicitada uma lista ao Conselho Regional de Farmácia de Minas Gerais (CRF-MG), que disponibilizou apenas a quantidade de farmácias inscritas. Os dados necessários para a pesquisa foram alcançados por meio de uma lista disponibilizada pela Vigilância Sanitária da cidade que constava a razão social, o endereço e o setor de localização da farmácia.

A presente pesquisa selecionou apenas as empresas optantes pelo regime de MPEs enquadradas corretamente e inscritas no CNPJ. Tais informações foram encontradas nas páginas online oficiais do Diário Oficial da União, ANVISA, JUCEMG, entre outros, utilizando como base de pesquisa os dados constantes na lista disponibilizada pela Vigilância Sanitária. Assim, consultou-se a página da Receita Federal do Brasil, no campo consulta de CNPJ, a situação cadastral das organizações para confirmar se estavam devidamente enquadradas no regime ME.

Na lista disponibilizada pela Vigilância Sanitária, constava um total de 244 empresas, entretanto, selecionou-se apenas 174 que se enquadravam nos requisitos citados anteriormente. Fez-se aplicação de questionários a todas, porém, obteve-se retorno de apenas 43, sendo que apenas 29 foram consideradas nos resultados. Isso ocorreu, pois uma parte dos 
respondentes ocupavam cargos que variaram entre balconista, atendente, farmacêutico, e outros.

A seleção específica de empresas cadastradas como MPE dá-se pela importância que elas têm na economia do país. Lima Júnior (2009) menciona o destaque das MPEs no mercado global, na geração de empregos e por representar 99,02\% das organizações existentes e $26 \%$ da renda total dos mercados industrial, comercial e de serviços.

A elaboração do questionário teve como base afirmações de autores sobre as definições de artefatos gerenciais, almejando identificar o nível de conhecimento do respondente. Foram elaboradas questões abertas, fechadas, de múltipla escolha, e algumas sem limitações de quantidade de alternativa a ser respondida, permitindo identificar a percepção dos respondentes sobre os artefatos gerenciais.

Os questionários foram aplicados por email, via formulário do Google Docs, pois essa ferramenta apresenta melhor dinâmica dos resultados, além de facilidade para os respondentes. Tabelas e gráficos foram utilizados para organizar, analisar e apresentar os resultados encontrados nos questionários aplicados.

\section{APRESENTAÇÃO DOS RESULTADOS}

Quanto à idade dos respondentes, três na faixa etária de 20 a 25 anos, onze entre 26 a 30 anos, cinco estão na faixa de 31 a 35 anos, seis entre 36 e 40 anos, dois têm de 41 a 45 anos e dois de 46 a 50 anos. As funções dos respondentes variaram entre Gerentes (dez, no total) e Empresário/Proprietário (somando dezenove).

Quanto ao grau de escolaridade dos respondentes, 17 são graduados, sendo oito em Administração, três em Ciências Contábeis, três em Economia e três em Engenharia de Produção (sendo esses os Empresários/Proprietário).

O surgimento das grandes redes de farmácia pode ser notado não somente no centro da cidade, como também nos bairros, e causa vários impactos no mercado farmacêutico. Para verificar quais seriam essas consequências, perguntou-se o seguinte aos respondentes: "Você acredita que o crescimento das grandes redes de drogarias na cidade tem pressionado o mercado?" As respostas evidenciaram que 93\% dos respondentes acreditam que sim e 7\% acreditam que não. Isso gera uma preocupação com a competitividade, capacidade de acompanhar o setor e com a identificação do melhor método a ser utilizado.

Cunha, Vasconcelos e Afonso (2010) destacam que, com a globalização, vieram também as transformações aceleradas, a exigência dos clientes e o excesso de produtos no 
mercado com maior qualidade e um menor ciclo de vida. Esse cenário faz com que as empresas adotassem ferramentas gerenciais que alcancem a eficiência, almejando a capacidade competitiva e a sobrevivência.

Diante da concordância de 27 respondentes fez-se necessário identificar quais são os motivos. A Tabela 1 apresenta em quantidade e percentual as respostas encontradas, destacando que nessa questão poderia ser selecionada mais de uma alternativa para resposta, portanto, a soma ultrapassará $100 \%$.

Tabela 1: Resumo em quantidade de respostas sobre os motivos do crescimento das grandes redes de drogarias.

\begin{tabular}{lcc}
\hline \multicolumn{1}{c}{ Motivos do crescimento } & Quantidade & Porcentagem \\
\hline Preço dos Medicamentos & 20 & $74 \%$ \\
Acessibilidade & 7 & $26 \%$ \\
Popularidade & 14 & $52 \%$ \\
Promoções & 4 & $15 \%$ \\
\hline
\end{tabular}

Fonte: dados da pesquisa.

Os resultados comprovaram que 20 dos respondentes acreditam ser o "Preço dos Medicamentos" o real motivo da pressão realizada pelas grandes redes. Descartando que "Acessibilidade", "Promoções" e "Popularidade" também foram citados.

O poder de barganhar o preço é considerado pelos respondentes um diferencial entre os empresários e gerentes de farmácia, aumentando assim o nível de competitividade da organização. É importante destacar essa questão, pois as organizações se deparam com inúmeras questões complexas presentes no cenário comercial do Brasil. A concorrência é uma das dificuldades encontradas por elas neste contexto. Cunha (2005) afirma que o ambiente em que a empresa está inserida é cada vez mais competitivo, e que a criatividade e a iniciativa unidas à tecnologia são peças fundamentais para o alcance do sucesso organizacional.

Neste contexto, esperou-se conhecer melhor a organização e identificar falhas em seu sistema gerencial. Para tanto, foi questionado se a empresa possui algum tipo de planejamento interno, que forneça informações como os custos que devem ou não ser alocados a determinados produtos. As respostas mostraram que 55\% afirmam possuir algum método de planejamento interno, contra $45 \%$ que não possuem.

Porém, o fato de que essas empresas terem um meio de planejamento, não basta para verificar a eficiência do processo. É necessário conhecer quais as funcionalidades e finalidades dos artefatos gerenciais, para identificar o ideal para determinada organização, e alcançar a eficiência no processo de planejamento interno. Fez-se necessário compreender o nível de conhecimento dos respondentes referentes aos artefatos estudados. Aplicou-se 
questões que buscaram identificar se conheciam ou já tinham ouvido falar dos artefatos gerenciais ou de alguma característica e definição destes.

A Tabela 2 apresenta quais artefatos são conhecidos pelos respondentes, lembrando que nessa questão poderia ser selecionada mais de uma alternativa por resposta, portanto, a somatória das porcentagens ultrapassará $100 \%$.

Tabela 2: Resumo em quantidade de respostas sobre artefatos conhecidos pelos respondentes

\begin{tabular}{|c|c|c|}
\hline Artefato & Quantidade & Porcentagem \\
\hline $\mathrm{BSC}$ & 3 & $12 \%$ \\
\hline GECON & 5 & $20 \%$ \\
\hline $\mathrm{ABC}$ & 6 & $25 \%$ \\
\hline TOC & 2 & $8 \%$ \\
\hline EVA & 3 & $12 \%$ \\
\hline $\mathrm{MC}$ & 7 & $29 \%$ \\
\hline CUSTEIO POR ABSORÇÃO & 8 & $33 \%$ \\
\hline ORÇAMENTO & 11 & $45 \%$ \\
\hline
\end{tabular}

Fonte: dados da pesquisa

Verificou-se que 24 dos respondentes conhecem, ou ouviram falar, sobre os artefatos. Nota-se que as ferramentas Orçamento e Custeio por Absorção são as mais populares entre os respondentes. Os demais artefatos, como demonstrado na tabela, não são tão conhecidos, sendo que 10 dos respondentes os conheceram na graduação, cinco em cursos técnicos, quatro em jornais e revistas, três em livros, três por pessoas conhecidas e na pós-graduação.

Seguindo com a pesquisa, questionou-se também se os respondentes discernem, dentre esses artefatos conhecidos, determinadas características, como quais deles são inovadores e quais são tradicionais. A Tabela 3 evidencia as respostas encontradas pela presente pesquisa.

Tabela 3: Resumo em quantidade de respostas sobre quais artefatos considerados INOVADORES

\begin{tabular}{|c|c|c|}
\hline Artefato & Quantidade & Porcentagem \\
\hline BSC & 13 & $54 \%$ \\
\hline $\mathrm{ABC}$ & 7 & $29 \%$ \\
\hline GECON & 3 & $12 \%$ \\
\hline EVA & 5 & $20 \%$ \\
\hline TOC & 2 & $8 \%$ \\
\hline CUSTEIO POR ABSORÇÃO & 1 & $4 \%$ \\
\hline $\mathrm{MC}$ & 3 & $12 \%$ \\
\hline ORÇAMENTO & 4 & $16 \%$ \\
\hline
\end{tabular}

Fonte: dados da pesquisa

Considerando-se as informações levantadas (Tabela 3), observou-se que 13 dos respondentes veem o BSC como um artefato inovador, e outros, considerados inovadores pelos autores estudados e não são citados em grandes proporções, como ocorrido com o BSC. As ferramentas gerenciais inovadoras se caracterizam por ser dinâmicas e possibilitam 
encontrar o valor do custo dos produtos, fretes e todo contexto e diversidade, conforme Ribeiro (2012). Entre os citados na questão, os que se encaixam na definição, conforme autores consultados, são (ABC), (BSC), (TOC), (EVA) e (GECON).

$\mathrm{O}$ fato de que existir uma resposta unânime representa a ausência de conhecimentos específicos referentes às ferramentas existentes, que podem auxiliar os empresários e funcionários a alavancar resultados e controles internos.

A seguir é apresentada a Tabela 4, que relata a quantidade de respostas obtidas entre os 24 respondentes que conhecem ou já ouviram falar sobre os artefatos, consideradas tradicionais pelos respondentes. Esta questão permitia selecionar mais de uma alternativa por resposta, portanto a somatória das porcentagens ultrapassará $100 \%$.

Tabela 4: Resumo em quantidade de respostas sobre quais artefatos considerados TRADICIONAIS

\begin{tabular}{lccc}
\hline & Artefato & Quantidade & Porcentagem \\
\hline BSC & 3 & $12 \%$ \\
ABC & 4 & $16 \%$ \\
GECON & 2 & $8 \%$ \\
EVA & 3 & $12 \%$ \\
TOC & 4 & $16 \%$ \\
CUSTEIO POR ABSORÇÃO & 9 & $37 \%$ \\
MC & 4 & $16 \%$ \\
ORÇAMENTO & 8 & $33 \%$ \\
\hline
\end{tabular}

Fonte: dados da pesquisa

Com os artefatos tradicionais, identificados como Custeio por Absorção, MC e Orçamento, identifica-se a mesma carência, pois apenas um dos artefatos tradicionais é citado em grande porcentagem. Pode-se relacionar o motivo desse quadro com o fato de que a maioria dos respondentes são graduados em administração e três em engenharia de produção, e no curso de ciências contábeis existem apenas três respondentes.

Para identificar a carência da organização em relação à adoção e à percepção dos artefatos gerenciais, questionou-se se haveria possibilidade de aplicação de uma ferramenta gerencial. Como respostas, observou-se que 86\% (25 dos respondentes) estão dispostos a aplicar os artefatos. Mesmo que com pouco conhecimento sobre estes artefatos, perguntou-se aos 25 respondentes quais dos artefatos gerenciais apresentados eles estariam dispostos a adotar. A seguir a Tabela 5 contempla os resultados encontrados.

Tabela 5: Resumo em quantidade de respostas sobre a perspectiva de adoção dos artefatos gerenciais

\begin{tabular}{|c|c|c|}
\hline Artefato & Quantidade & Porcentagem \\
\hline $\mathrm{BSC}$ & 4 & $16 \%$ \\
\hline $\mathrm{ABC}$ & 9 & $37 \%$ \\
\hline GECON & 4 & $16 \%$ \\
\hline EVA & 5 & $20 \%$ \\
\hline
\end{tabular}

REMIPE- Revista de Micro e Pequenas Empresas e Empreendedorismo da Fatec Osasco V. 3, N¹, jan.-jun. 2017. 


\begin{tabular}{lcc}
\hline TOC & 0 & $0 \%$ \\
CUSTEIO POR ABSORÇÃO & 6 & $25 \%$ \\
MC & 9 & $37 \%$ \\
ORÇAMENTO & 11 & $45 \%$ \\
\hline
\end{tabular}

Fonte: dados da pesquisa

Notou-se uma maioria disposta a adotar a MC, ABC, Custeio por Absorção e Orçamento, e outras citadas, que são classificados pelos autores como artefatos tradicionais.

Uma das questões apresentadas pelo questionário são conceitos e definições dos artefatos gerenciais, inovadores e tradicionais, foi perguntado ao respondente se ele concorda totalmente ou parcialmente, se não concorda nem discorda e se discorda totalmente ou parcialmente destas afirmações. Identificou-se que a maioria concorda parcialmente com as afirmações, de definição dos artefatos gerenciais, mas entre as respostas destaca-se o orçamento, por possuir o maior número de respostas: concordo totalmente.

Este questionamento auxiliou a traçar um perfil dos respondentes, pois identificou que o público do setor farmacêutico tem um maior conhecimento, disponibilidade e aceitação pelo artefato gerencial denominado Orçamento.

Questionou-se se os respondentes reconhecem que os artefatos inovadores, como o BSC e ABC, podem auxiliar em questões gerenciais como a formação do preço de venda. Como resposta, 93\% dos respondentes afirmaram que acreditam que estes modelos inovadores gerenciais auxiliam, sim, na gestão da organização.

Buscando ajudar o setor farmacêutico, foi perguntado em qual das atividades ou áreas da farmácia têm uma carência e poderia receber um desses artefatos. Como resposta, 12 dos respondentes buscam melhorias no setor de planejamento de resultado e gestão de custos diversos, porém a maioria preocupa-se com a formação de preço de venda.

Foram feitas algumas observações pelos respondentes, de cunho relevante para essa pesquisa: i) "Acabo de perceber que não compreendo muito assuntos contábeis, mas espero ter ajudado"; ii) "Desculpe-me pelas respostas, mas não conheço o assunto e nenhum desses artefatos".

Ficou claro que as MPEs conhecem um pouco dos artefatos, porém não os compreendem profundamente e não os utilizam como ferramentas administrativas e gerenciais, o que poderia fornecer melhores resultados econômicos.

\section{CONSIDERAÇÕES FINAIS}

O objetivo do artigo foi identificar a percepção dos gestores das Micro e Pequenas 
Empresas (MPEs) mineiras do setor farmacêutico sobre os artefatos gerenciais tradicionais e inovadores, e as perspectivas da sua adoção. Para tanto, foi realizada uma pesquisa do tipo survey com 29 farmácias de uma cidade de grande porte localizada no estado de Minas Gerais

A percepção sobre os artefatos gerenciais e a perspectiva da adoção pelas MPEs do setor farmacêutico é confirmada pela pesquisa, que demonstrou que, além dos respondentes possuírem um conhecimento básico sobre os artefatos, $17 \%$ deles não conhecem os artefatos e os $83 \%$ restantes conhecem ou já ouviram falar.

Também se confirmou a ideia de que há interesse em adoção e possíveis aplicações de modelos gerenciais pelas organizações farmacêuticas, sendo que 25 dos respondentes afirmaram estar dispostos a adotar um dos artefatos gerenciais. $\mathrm{O}$ resultado obtido identificou o perfil dos respondentes, assim como conhecimento e interesse sobre os artefatos gerenciais estudados.

Notou-se que existe uma noção sobre os artefatos gerenciais, o que são e como funcionam, porém são conhecimentos básicos, que não possibilitam estruturar gerencialmente uma organização. Verificou-se a dificuldade de classificar os artefatos em inovadores e tradicionais, e que nenhuma das respostas selecionaram todos os exemplos de modelos gerenciais inovadores assim como os tradicionais, conforme Tabela 3 e 4.

Portanto, o objetivo do trabalho foi alcançado, sendo que um dos motivos para se realizar essa pesquisa foi a concorrência com as grandes redes e o sufocamento que as MPE sofrem em um mercado cercado por grandes redes farmacêuticas. O presente trabalho identificou o grande diferencial desta questão, apresentando resultados que esclareceram que as pequenas empresas do setor farmacêutico não possuem embasamento e conhecimento teórico específico em áreas de gestão, como os artefatos, enquanto as grandes redes as utilizam como princípios administrativos.

Espera-se que este trabalho contribua teoricamente como fonte de pesquisa futura no setor selecionado, e também se espera que ele contribua na prática, auxiliando na gestão das organizações farmacêuticas, como base no processo de gestão e tomada de decisões, nas MPEs, destacando que há um vasto campo a ser explorado no setor farmacêutico.

De maneira geral, a pesquisa realizada possui algumas limitações destacadas a seguir: i) Por ser um levantamento por meio de questionários, pode ocorrer de algum aspecto, não ter sido analisado; ii) A região onde foi realizada a pesquisa também limita o estudo, pois não se aplica às organizações fora da cidade pesquisada; iii) É um estudo limitado a MPEs apenas do setor farmacêutico, e não se conhece a percepção dos gestores do setor como um todo; iv) 
Escassez de trabalhos publicados abordando temas gerenciais aplicados ao setor farmacêutico; v) Alguns respondentes foram excluídos da pesquisa, pois as suas funções variavam entre balconista, farmacêutico, atendente e outros.

Sugere-se para futuras pesquisas, estudar modelos de gestão específicos para microempresas do setor farmacêutico, aprofundar e expandir a pesquisa para outros setores, ampliar a pesquisa no setor farmacêutico em outras regiões do país, e também estudar o setor farmacêutico sob outros enfoques.

\section{REFERÊNCIAS}

ABBAS, K.; GONÇALVES, M. N.; LEONCINE, M. Os métodos de custeio: vantagens, desvantagens e sua aplicabilidade nos diversos tipos de organizações apresentadas pela literatura. ConTexto: Revista do Núcleo de Estudos e Pesquisas em Contabilidade. Porto Alegre, v. 12, n. 22, p. 145-149, $2^{\circ}$ semestre de 2012.

AGUIAR, A. B. de; FREZATTI, F. Escolha da estrutura apropria de um Sistema de Controle Gerencial: uma proposta de análise. Revista de Educação e Pesquisa em Contabilidade. Brasília, v. 1, n. 3, p. 21-44, set./dez. 2007.

ANGONESE, R.; SANTOS, P. S. A. dos. LAVARDA, C. E. F.Valor Econômico Agregado (VEA) e estrutura de capital em empresas do IBRX 100. ConTexto: Revista do Núcleo de Estudos e Pesquisas em Contabilidade, Porto Alegre, v. 11, n. 20, p. 7-17, $2^{\circ}$ semestre de 2011.

BACKS, J. A. EVA- VALOR ECONÔMICO AGREGADO. ConTexto: Revista do Núcleo de Estudos e Pesquisas em Contabilidade, Porto Alegre, v. 2, n. 3, $2^{\circ}$ semestre de 2002.

BASSO, L. F. C.; OLIVEIRA, S. F. de.; KAYO, E. K. Ajustes Contábeis para o cálculo do EVA: estudo sobre os procedimentos adotados em empresas brasileiras. Contextus: Revista contemporânea de economia e gestão. Fortaleza, v. 6, n. 1, p. 39-58, jan./abr. 2008.

BRASIL, M.V.O.; NOGUEIRA, C.A.G.; FORTE, S.H.A.C. Schumpeter e o Desenvolvimento Tecnológico:uma visão aplicada às pequenas e médias empresas

(PMEs). Revista de Ciências da Administração, Florianópolis, v.. 13, n. 29, p. 38-62, jan./abr., 2011.

CARÍSSIMO, C. R.; MATIAS, M. A.; CALLADO, A. L. C. Teoria das Restrições: Análise da aplicação empírica do processo de pensamento em uma empresa de homecare. Advances In: Scientific and Applied Accounting. São Paulo, v. 5,n. 1, p. 80-98, 2012.

CARVALHO JUNIOR, C. V. O. et al. Uso da Margem de Contribuição em Controladoria: um estudo de caso em empresa de transporte urbano de passageiro. Revista de contabilidade do mestrado em ciências contábeis da UERJ, Rio de Janeiro, v. 14, n. 2,p.2-17, mai./ago. 2009 
CASTANHEIRA, D. F. R.; LUPORINI, C.E.; SOUSA, A. F., ROJO, C.A. O Uso do Orçamento Empresarial como Ferramenta de Apoio à tomada de decisão e ao controle gerencial: um estudo comparado em indústrias farmacêuticas de médio porte. Revista de Finanças Aplicadas. São Paulo, v. 1, p. 1-20, 2013.

CATELLI, A. Controladoria: uma abordagem da gestão econômica GECON.São Paulo: Atlas, 2007.

COSTA, Ana Paula Paulino. Balanced Scorecard: conceitos e guia de implementação. São Paulo: Atlas, 2006. 90 p.

CUNHA, N. C. V. As práticas gerenciais e suas contribuições para a capacidade de inovação em empresas inovadoras. Tese de Doutorado, Universidade de São Paulo, São Paulo, SP, Brasil, 2005.

CUNHA, C.;VASCONCELOS, M.C.; AFONSO, T.Análise das Práticas de Gestão do Conhecimento de Empresas do setor Farmacêutico no Brasil. Revista Gestão \& Tecnologia. Pedro Leopoldo, V. 7 , n. 2, p. 1-14, ago./set.,2010.

DIEHL, C. A.; SOUZA, M. A. Publicação sobre custeio baseado em atividades (ABC) em congressos brasileiros de custos no período de 1997 a 2006. Revista Contabilidade Vista e Revista. Universidade Federal de Minas Gerais, Belo Horizonte, v. 19, n. 4, p. 39-57, out./dez. 2008.

FREITAS, E.C.; BARTH, M. De Pai Para Filho: a complexidade e os desafios da gestão das empresas familiares. Revista de Administração Universidade Federal de Santa Maria(UFSM). Santa Maria, v.5, n.3, p. 549-568, set.ldez., 2012.

FREZATTI, F. Beyond Budgeting: inovação ou resgate de antigos conceitos do orçamento. Empresarial. Revista. Scielo Scientific Electronic Library Online. São Paulo, v. 45, n. 2,abr./jun., 2005.

FREZATTI, F. Orçamento Empresaria: planejamento e controle gerencial. 2 ed. São Paulo: Atlas, 2008. $38 \mathrm{p}$.

GUERREIRO, R. CORNACHIONE JUNIOR, E. B., SOUTES, D. O. Empresas que se destacam pela qualidade das informações a seus usuários externos também se destacam pela utilização de artefatos modernos de contabilidade gerencial? Revista de Contabilidade \&Finanças, Universidade de São Paulo -USP, São Paulo, v. 22, n. 55, p. 88-113, jan./fev./mar./abr. 2011.

HASHIMOTO,N. Y.; FONSECA,V. S. da. Pressões Ambientais e Respostas Estratégicas: uma análise de organizações do varejo farmacêutico curitibano. Revista Eletrônica de Administração. Universidade Federal do Rio Grande do Sul, Rio Grande do Sul, v. 15, n. 2, mai./ago., 2009.

HEINZMANN, L.M.; LAVARDA, C.E.F. Cultura Organizacional e o Processo de Planejamento e Controle Orçamentário. Revista de Contabilidade e Organizações. Ribeirão Preto- São Paulo, v. 5, n. 13, p. 4-19, set. Idez., 2011 
LEONE, G. S. G. Custos: planejamento, implantação e controle.São Paulo: Atlas, 2000.

LIMA, E.; M. ESPEJO, M. B.; PEREIRA, C. A.; FREZATTI, F. As Respostas do GECON às Críticas do Relevance Lost. Revista de Contabilidade Vista \& Revista. Universidade Federal de Minas Gerais, Belo Horizonte, v. 22,n. 1, p. 177-200, jan./mar. 2011.

LIMA JÚNIOR, J. F. A. Estratégia e longevidade das Micro e Pequenas Empresas. 2009. 86 p. Tese (Mestrado em Gestão de Empresas)- Instituto Superior de Ciências do Trabalho e da Empresa- ISCTE Business School, Lisboa, 2009.

MARTINS, E.; ROCHA, W. Métodos de Custeios comparados: custos e margens analisados sob diferentes perspectivas. São Paulo: Atlas, 2010. 72-74 p.

NAKAGAWA, M. ABC: custeio baseado em atividades.2 ed. São Paulo: Atlas, 2001. 32p.

NASCIMENTO, S. et al.Ferramentas gerenciais à luz do desempenho organizacional. Revista Pretexto, Belo Horizonte, v. 11, n. 3, p. 33-57, jul./set. 2010.

OLIVEIRA, A.A.; PAPA, A.C. A influência da Cultura Organizacional no Processo de Profissionalização da Gestão em uma Empresa Familiar. Revista de Administração Universidade Federal de Santa Maria- (UFSM). Santa Maria, V.2, N.2, P.385- 398, set.Idez., 2009.

PERTY, L. I.; NASCIMENTO, A. M. Um Estudo Sobre o Modelo de Gestão e o Processo Sucessório em Empresas Familiares. Revista de Contabilidade e Finanças. São Paulo, v. 20, n. 49, p. 109-125, jan.labr. , 2009.

RAUPP, F. M.; BEUREN, I. M. Metodologia da Pesquisa Aplicável s Ciências Sociais. in: BEUREN, I. M ( Org.). Como elaborar Trabalhos Monográficos em Contabilidade. São Paulo, Atlas, 2009.

RIBEIRO, M.M. M. A aplicação dos ABC no cálculo dos custos logísticos: o caso de Castro \& Guimarães- distribuição. 2012.172p. Tese (Mestrado em Engenharia e Gestão Industrial)Universidade do Minho, escola de engenharia.

SANTOS, R. V. Controladoria: uma introdução ao sistema de gestão econômica GECON.São Paulo: Saraiva, 2005.

SILVA, A. B.; ROSSETTO, C. R. Os Conflitos entre a Prática Gerencial e as Relações em Família: uma abordagem complexa e multidimensional. Revista de Administração Contemporânea. Curitiba, V. 14, n. 1,p. 40-60, jan.Ifev. ,2010. 40-60, Jan./Fev., 2010.

SILVA, A. S.; ALVES, L. C. O.; COGAN, S.Integrando o custeio baseado em atividades com a teoria das restrições: a aplicação do $\mathrm{ABC}$ operacional em uma odontoclínica. Revista de Administração Mackenze, Brasília, v. 8, n. 4, p. 81-102, 2007.

SILVA, C. A. T. Utilização do custeio por absorção para fins gerenciais. Contabilidade, Gestão e Governança. Brasília, v. 1, n. 1, 1998. 
SILVA, J. O.; LAVARDA, C. E. F.O relacionamento entre a contabilidade gerencial e o processo de planejamento:estudo em uma holding. Contabilidade, Gestão e finanças. Brasília, V. 12, n.3, p. 3-13, set.ldez., 2009.

SCHUBERT, P. Manual de Orçamento Empresarial Integrado. Rio de Janeiro: Jolan, 1987.

STEWART, G. B. The quest for value: a guide for senior managers. EUA: HarperCollins, 1999.

VILAS BOAS, A. A. ;JONES, G. D. C. Planejamento financeiro e controle orçamentário: um estudo de caso em uma empresa industrial. Revista Contemporânea de Economia e Gestão Constextus, Fortaleza, v. 3, n. 1, p. 25-34, jan. \jun., 2005.

WAIANDT, C;DAVEL, E. Organizações, Representações e Sincretismo: a Experiência de uma Empresa Familiar que Enfrenta Mudanças e Sucessões de Gestão. Revista de Administração Contemporânea. Curitiba, V. 12, n. 2, p. 369-394,abr.ljun., 2008.

WERNKE, R; BORNIA, A. C. Balanced Scorecard: considerações e comentários. In: Congresso Brasileiro de Custos, 8. 03 a 05 de outubro de 2001 - São Leopoldo/RS. Anais... São Leopoldo: Associação Brasileira de Custos, 2001. 